ЗИНОВЬЕВ Андрей Олегович - кандидат политических наук, доцент кафедры теории и философии политики Санкт-Петербургского государственного университета (191124, Россия, г. СанктПетербург, ул. Смольного, 1/3, 7-й под.; azin73@таil.ru)

ЛИНДЕ Андрей Николаевич - кандидат политических наук, доцент кафедры регионального управления и национальной политики Одинцовского филиала Московского государственного института международных отношений (университета) (117437, Россия, г. Москва, ул. Островитянова, 9, корn.4., nод.2; anlinde@mail.ru)

МИРОНОВА Дагмар Вали Герта - кандидат философских наук, доцент кафедры истории и теории политики Московского государственного университета им. М.В. Ломоносова (119192, Россия, 2. Москва, Ломоносовский пр-кт, 27, корn. 4; dagmar@таil.ru)

СЫТИН Андрей Георгиевич - кандидат философских наук, доцент кафедры философии политики и права Московского государственного университета им. М.В. Ломоносова (119192, Россия, 2. Москва, Ломоносовский пр-кт, 27, корп. 4; a_sytin@таil.ru)

\title{
ДИАЛОГ КАК ВОСПРИЯТИЕ ДРУГОГО В ПОЛИТИКЕ
}

\section{(аналитический обзор докладов круглого стола, посвященного 90-летию Ю. Хабермаса)}

Аннотация. В докладах на круглом столе были представлены разные аспекты научных работ Ю. Хабермаса. Докладчики анализировали нормативные темы, такие как творческое наследие Хабермаса и современная политическая мысль, его теория коммуникативного действия и концепция делиберативной демократии, восприятие государства и революции, природа политического и публичная сфера. Также доказывалась применимость нормативно-теоретических концепций Хабермаса к реальности - в прикладной политической науке и в разрешении человеческих, социальных проблем на практике.

Ключевые слова: Ю. Хабермас, диалог, вовлечение Другого, применение нормативных положений в политической науке и в социальной действительности

Qапреля 2019 г. в МГИМО прошел организованный РАПН круглый стол «Диалог как восприятие Другого в политике», посвященный 90-летию Ю. Хабермаса. В нем приняли участие более 30 человек из 10 вузов Москвы, Санкт-Петербурга, Государственной думы РФ, Ассоциации преподавателей Москвы, Фонда ИНДЕМ. Их внимание привлекли доклады специалистов из МГУ имени М.В. Ломоносова, СПбГУ, МГИМО.

Участие в организации данного круглого стола приняли члены РАПН В.Г. Ледяев, Л.Н. Тимофеева, М.Н. Шестакова, А.Н. Линде.

В первом докладе Д. Миронова, специализирующаяся в области немецкой философии, переводчик ряда трудов Хабермаса, проанализировала не переведенную на русский язык работу Хабермаса 1976 г. «О “Понятии власти” у Х. Арендт». Эта работа Ю. Хабермаса, при всей оригинальности обоих мыслителей, впервые показала взаимосвязь и, по существу, совместимость их идей.

Ю. Хабермас не только является одним из наиболее авторитетных в академической философии, но и одним из наиболее активных участников политических дискуссий в публичной сфере. С этим связано то, что Хабермас часто выбирает для своих работ форму эссе.

Хабермас разделял точку зрения Арендт о том, что власть не есть результат насилия, а результат взаимодействия, диалога членов общества, нацеленного 
на взаимопонимание. Хабермас развил идеи рациональности такого диалога и задачи власти по сохранению подобной практики.

Безусловно, все политические трактаты устремлены на анализ центральной политической категории - категории власти. Но Ю. Хабермас отступает от известного понимания М. Вебера, согласно которому власть - «способность индивида А заставить индивида В выполнять действия в своих интересах». Философу ближе подход Х. Арендт: «Власть - это способность граждан действовать ради общего блага, договорившись друг с другом в непринужденной коммуникации».

Но такая трактовка власти предполагает и другой подход к пониманию сущности человеческого действия. М. Вебер понимал под действием властвующего человека целерациональное действие, направленное на определенную цель и предполагающее управление другими. В противоположность ему, Х. Арендт предполагает иной тип действия - взаимодействие людей в коммуникации для взаимовыгодного достижения цели, основанное на договоренности, а не на управлении. Это предполагает взаимодействие людей в коммуникации, направленной на взаимопонимание. Здесь Ю. Хабермас добавляет свою концепцию коммуникативного действия. «Власть формируется в коммуникативном действии, она - групповой эффект речи, внутри которой для всех участников понимание выступает самоцелью. Но если власть больше не мыслится как потенциал для осуществления целей, если она не актуализируется в целерациональных действиях - в чем она тогда выражается, для чего она может служить?» - задавался вопросом Хабермас. С его точки зрения, позитивная власть выражается в порядках, защищающих политическую свободу; в сопротивлении силам, угрожающим политической свободе извне или изнутри; в государственно-гражданских политических актах, после которых основываются новые институты свободы.

Для этого требуется достижение интерсубъективности между гражданами, когда у них без принуждения формируется общее понимание картины мира, учитывающее точки зрения всех и каждого в отдельности. Поэтому общий жизненный мир людей формируется на основе плюрализма мнений всех граждан.

Особенно важно, что, исходя из такого понимания власти, государственная администрация не может быть основана на насилии. Любая власть в обществе может ненасильственно складываться только в свободном утверждении гражданской общественности. А политическая общественность утверждает власть только до тех пор, пока люди взаимодействуют по принципам неискаженной коммуникации, выявленным Ю. Хабермасом.

Таким образом, именно исходя из такого понимания свободно формируемой в коммуникации власти, возможно создать в политической науке другую парадигму мышления, основанную на свободе, равенстве и взаимопонимании граждан, вне какого-либо насилия и принуждения со стороны бюрократического аппарата. Эта парадигма прямо противоположна «инструментальному» пониманию власти и насилию, оказываемому со стороны государственных и экономических структур.

A.O. Зиновьев в докладе «Значение идей Ю. Хабермаса для исследований государств и революций» раскрыл подход Хабермаса к революции как к разрушению одного дискурса другим, приходящим ему на смену, и отношение ученого к власти бюрократии, безнаказанно осуществляющей насильственный дискурс. Именно поэтому рациональные публичные дискурсы граждан должны перепроверять все стремления бюрократии, а также продуманно контролировать, ограничивать и перенаправлять их не в интересах отдельных лиц, а для блага всего общества. 
Как может показаться, Хабермас просто устарел, его идеи не актуальны для современного понимания революционных процессов или повседневного воспроизводства государства [Зиновьев, Чеботарева 2013]. Но это не так.

С одной стороны, изучающие государство имя Хабермаса упоминают редко. Исследователей революций можно разделить на историков и социологов. В исторических исследованиях революций довольно часто упоминается работа Хабермаса «Структурное изменение публичной сферы». Например, историк Р. Шартье в работе «Культурные истоки Французской революции» предложил историческую проверку тезиса Хабермаса о трансформации публичной сферы в ходе Великой французской революции.

Среди социологов ключевое значение принадлежит идеям Т. Скочпол и ее учеников, прочно связавших исследования революций с исследованиями государств. Но эта школа развивает марксистско-материалистическую методологию Ленина, а не оригинальную новую методологию, отошедшую от структуралистского марксизма, интегрирующую феноменологический и системнофункциональный подходы, преобразующую социологические подходы на основе разделения «жизненного мира» и «системы». Эта методология предложена Ю. Хабермасом.

Тема революции проходит через многие работы Хабермаса. В своей трактовке революций Хабермас примыкает к работам историков. Ключевая работа Хабермаса «Теория коммуникативного действия» посвящена проблемам социологической теории, и государство анализируется в данной работе в контексте «позднего капитализма». Как и в более ранней работе «Проблема легитимации позднего капитализма», государство в творчестве Хабермаса вступает скорее как фон, а не как основной объект исследования. Больше внимания уделено государству в работе Хабермаса «Фактичность и значимость», но государство в ней понимается посредством обращения к правовой традиции, скорее в рамках правоведения, а не социологии.

Но, с другой стороны, исследования Ю. Хабермаса особенно важны для понимания сущности государств и революций.

Хотя в своих работах Хабермас зависит от социологических идей Т. Парсонса и Н. Лумана, использует чаще понятие «политическая система», а не понятие «государство», но он критикует социологическую теорию систем. Его обращение к правовому пониманию государства в работе «Фактичность и значимость», отождествление государства и демократии означает веру в значимость права и прав человека. Хабермас не согласен с идеями М. Фуко о «власти-знании», под влиянием которых находится большинство современных исследователей феномена государства. Понимание государства можно реконструировать как диалектику стратегической и коммуникативной рациональностей, это вносит важное уточнение в особенности роли государства в революционных процессах.

Работы Хабермаса о революционных процессах действительно написаны на основе идей историков и развивают исторические подходы к исследованиям революций. Но в своих работах Хабермас одним из первых делал акцент на социологическом измерении революционных процессов. Популярность исследования «Структурное изменение публичной сферы» во многом определяется его новаторским характером. В нем Хабермас не только использовал структурный подход к анализу революций до появления структурного подхода Т. Скочпол, но и показал необходимость соединения подходов историков и социологов для многомерного понимания характера революционных процессов. В своей ранней работе Хабермас уже показал ключевую роль государства в формировании структурного типа публичной сферы. В последующих работах Хабермас уточнил характер современного государства и его взаимосвязь с новыми социаль- 
ными движениями. Эти его работы отчасти совпадают с последующими исследованиями Т. Скочпол и показывают роль социального государства как современного дополнения правового государства и демократии, необходимого для стабилизации либеральных демократий в США и в Германии.

Классические (или «буржуазные») революции имели место в условиях досовременных (то есть, недемократических) государств, в которых, как показал ученик Скочпол Д. Гудвин, наблюдалась слабая инфраструктурная власть государственной бюрократии, т.е. государство было способно только слабо влиять на повседневную жизнь своего населения. В современных либеральных демократиях сила бюрократического государства частично уравновешена правами человека и социальным государством, т.е. существует диалектика стратегической рациональности государственной бюрократии и коммуникативной рациональности демократической публичной сферы. В современных аналогах «старого порядка» данная диалектика не работает, а обратной стороной полного господства стратегической рациональности государственной бюрократии является постоянная вероятность революции в недемократических странах.

A.Г. Cымин посвятил выступление теме «Ю. Хабермас как философ диалога в политике», его философии политики и права, которые выступают вместе и представлены им как форма регуляции общественной жизни. Ученый старался преодолеть в политическом крайнюю степень конфликтности. Он задавался вопросом: как обезопасить единство общества, как сохранить при этом неприкосновенность человеческого достоинства, выступал за постоянно действующий дискурс как дискуссию, которая должна быть подчинена общим правилам.

Этика дискурса, по Хабермасу, характеризуется тем, что он формулирует четкие рациональные правила: ни одна из сторон, затрагиваемых предметом обсуждения, не должна исключаться из дискурса (требование общего блага); все участники должны иметь равную возможность предъявлять претензии на общезначимость и критиковать других (автономия); участники должны быть готовы и способны «вчувствоваться» (to empathize) в претензии других на общезначимость (принятие идеальных ролей); существующие между участниками различия в смысле обладания властью не должны оказывать воздействие на выработку консенсуса (нейтральность); наконец, участники должны открыто разъяснить свои цели и намерения (прозрачность).

Хабермас - наследник и носитель великой мыслительной традиции. Так, в его философствовании чувствуются как философская культура, идущая еще от классической немецкой философии, так и мощные критические импульсы, характерные для франкфуртской школы. Сегодня одновременно нормативный и исследовательский подход Хабермаса, безусловно, несводим только к постулатам «критической теории», однако принадлежность к этой традиции в его трудах по-прежнему ощущается.

Философские интересы мыслителя весьма широки. Но нужно заметить, что он никогда не был (и не стал) равнодушным к происходящему в обществе, к тенденциям его трансформации. Поэтому в его творчестве важное место занимает философия политики и права, которая при этом носит (как это было и в российской традиции, идущей от П.И. Новгородцева и его школы) неразрывный характер, образуя единую философию политики и права.

Разумеется, не случайно Хабермас обращается к такому фундаментальному концепту этой сферы, как концепт политического. Сложившееся понимание этого концепта в русле К. Шмитта Хабермаса не устраивает. Для К. Шмитта в трактовке этого понятия важны столкновение, вражда - конфликт, доведенный до предельной остроты, когда он уже не может быть разрешен мирными средствами. 
Для Хабермаса (в этом он в значительной степени наследует Ясперсу с его «философской верой» в коммуникацию) в центре осмысления фундаментальных проблем политики права - вопрос подлинной, неискаженной коммуникации. Так, философия политики и права в его размышлениях тесно переплетается с этикой, коммуникативистикой, теорией дискурса. Таким образом, у Хабермаса формируется столь важная для понимания его мыслительной системы в целом теория коммуникативного действия. От инструментального действия он отличает коммуникативное действие, цель которого - достижение взаимопонимания между людьми.

В духе этой неискаженной коммуникации и достижения взаимопонимания между людьми Хабермас трактует и политический процесс. Здесь в центре оказывается вопрос о формировании общей воли, служащей затем основой для принятия политических решений. Если, скажем, в концепции Руссо невозможно понять, откуда берется общая (точнее, по Руссо, «генеральная») воля, которая никогда не ошибается и ведет всегда прямиком к общему благу, то для Хабермаса именно процесс образования общей воли становится предметом специального анализа. Этот процесс он трактует именно в коммуникативном ключе, противопоставляя это понимание, в частности, некоторым либеральным трактовкам, для авторов которых акторы политического процесса выходят на политическую арену с уже полностью сформированными политическими интересами и мнениями. Хабермас же подчеркивает первостепенную важность именно открытого диалога, обмена мнениями, в процессе которого эти мнения как-то влияют друг на друга, обогащая взгляды каждого из участников.

Из этого и вырастает для Хабермаса концепция делиберативной демократии, в которой принцип большинства и связанный с ним процесс подготовки и принятия политических решений находится во внутренней сопряженности с процессом искания истины. С этим связана и его трактовка понятия дискурса как дискуссии, в которой может принять участие каждый, кто в этом заинтересован, и которая подчинена определенным непреложным правилам. Несомненно, мыслитель отдает себе отчет в том, что максималистские идеалы массового, компетентного и заинтересованного участия граждан в политике выглядят в обозримом будущем не слишком реальными, однако он считает возможным и достижимым, чтобы решения большинства принимались как рационально мотивированный результат дискуссии с участием всех заинтересованных лиц. Хабермас, впрочем, подчеркивает, что общественные дискурсы могут иметь резонанс лишь при условии широкого, активного и децентрализованного участия.

Несомненно, Хабермас отнюдь не равнодушен и к вопросу о положении личности в современном обществе - отсюда столь заметная в его творчестве проблематика жизненного мира (так, в одной из работ последних лет он ставит вопрос, как сохранить уважение к неприкосновенности человеческого достоинства). И одновременно - к вопросам макроуровня, таким как сущность глобализации или будущее демократии в мировом масштабе.

Он уделяет внимание и разработке форм демократического процесса вне рамок национальных государств. Ведь сегодня, по его мнению, происходит вытеснение политики рынком, разрушаются сами социальные предпосылки для широкого политического участия. Поэтому принимать вызовы глобализации разумным путем означает, по Хабермасу, разработать в новой, постнациональной ситуации новые формы демократического самоуправления обществ и их добровольных соединений.

Докладчики на круглом столе небезуспешно искали ответ на вопрос: каким образом нормативно-теоретические положения Хабермаса решают и проблемы 
современной узко понимаемой политической науки как political science и могут обеспечить ее дальнейшее развитие на благо всего общества.

$\boldsymbol{A . H . ~ Л и н д е ~ п р е д л о ж и л ~ п у т и ~ р е ш е н и я ~ э т о и ̆ ~ п р о б л е м ы ~ в ~ д о к л а д е ~ « Н о в и з н а ~ н о р - ~}$ мативно-теоретического подхода Ю. Хабермаса и его значение для развития современной политической науки». По его мнению, Хабермас не только на нормативно-теоретическом уровне повлиял на философию и социальные науки, но и на практическом уровне предложил выход из фундаментальных человеческих проблем, останавливающих подлинное развитие общества в информационную эпоху. Это следующие проблемы: ограничение информации для большинства общества в пользу достижения власти информационно доминирующих технократических элит; в этой ситуации жизнь и саму личность стремятся «сократить» до малой части информационного потока; само общество может быть редуцировано до не обладающих смыслами, эмоциями, а просто механически соединяемых людей-«элементов», когда все общество на смысловом уровне «сузилось» [Геллнер 2004: 125] до «последних ступенек возрастающей энтропии, где вероятность незначительна... статистические различия между индивидами равны нулю» [Винер 2001: 184].

Докладчик утверждает, что Ю. Хабермас выявил цельную, взаимосвязанную философскую систему, удачно соединяющую философские смыслы и некоторые концепции в социологии, политической науке, лингвистике, юриспруденции, религиоведении и т.д. Но, с его точки зрения, наиболее значимо в этом подходе, что Ю. Хабермас на нормативно-теоретическом уровне решил наиболее существенную проблему, находящуюся в центре всей нашей жизни сохранение подлинного человеческого достоинства и человеческой личности в информационную эпоху.

Значимость нормативных положений, разработанных Хабермасом, воспринята многими учеными. Но остается вопрос: как с помощью применения теоретических положений Ю. Хабермаса в политической науке можно решать эту проблему на практике? В положениях Хабермаса А.Н. Линде выделил 5 направлений, которые уже реализуются.

1. Благодаря одновременно нормативно-теоретической и применимой для эмпирических исследований двухуровневой теории общества Хабермаса в его теории коммуникативного действия на прикладном уровне можно анализировать давление со стороны «системы» (администрации, бизнес-структур) на жизненный мир людей - их естественные ценности, переживания, а затем показывать пути их защиты [Линде 2018].

2. Хабермас сделал важное нововведение в противоположность теории рационального выбора, утверждавшей, что существует только один тип человеческого действия, осуществляющегося как монологическое, прагматическое воздействие на Другого - целерациональное, инструментальное действие. Ученый социологически убедительно показал, что именно противоположное - осуществляющееся как диалогическое, ориентированное и на интересы других людей, взаимодействие с Другим, утверждающееся во взаимопонимании с людьми коммуникативное действие - лежит в сферах семьи, образования, социальной интеграции, социализации, т.е. в основе всех основных социальных взаимодействий.

Особенно значимо, что и в анализе мировой политики и международных отношений, как показывают Г. Мюллер и О. Кек, применение концепций коммуникативной рациональности, коммуникативного действия делает возможным как исследование отклонений от общего блага на международной арене (например, несогласованность действий по совместному уничтожению международного терроризма), так и разработку путей решения общих для всех нас 
проблемных вопросов на международной арене, путей достижения взаимопонимания между странами ${ }^{1}$ [Müller 1995].

3. Хабермас выявил принципы «идеальной речевой ситуации» и для высказываний дискутирующих - их «притязания на значимость», которым они должны удовлетворять, чтобы образовались подлинные взаимопонимание и консенсус. Вместе эти принципы соединяются в модель «формально-прагматического дискурса», которая может служить моделью обсуждений всех значимых проблемных социальных, политических вопросов, затрагивающих интересы разных сторон. Важно, что эти притязания на значимость уже операционализированы для критического дискурс-анализа [Cukier, Bauer, Middleton 2014] - исследований государственных, крупных административных и бизнес-решений, стремящихся определить жизнь людей. В итоге даются предложения, как могут быть выправлены искажения обсуждений и коммуникации в целом - для общего блага 2 .

4. Хабермас в одновременно нормативном и эмпирическом исследовании предложил оригинальную концепцию коммуникативной публичной сферы, отражающую свободный, естественный и независимый уровень политической коммуникации в обществе, формирующий естественное, независимое, рефлексивное, а не запрограммированное общественное мнение. На основе концепции на общегосударственном уровне изучается, насколько свободна, независима публичная сфера в стране и в какой степени ее принципы формирования общественного мнения соответствуют идеальным принципам, выявленным Хабермасом. Эти исследования проведены российскими и зарубежными учеными [Публичная сфера... 2013].

5. Но особенно важна для политической науки модель делиберативной демократии, введенная Ю. Хабермасом, которая выявивила необходимость непосредственного влияния гражданского общества на государственную власть при помощи непосредственного, рефлексивного, вовлекающего все заинтересованные стороны открытого публичного обсуждения государственных проектов и предложения продуманных и рациональных инициатив. Эти положения уже подтвердились в Центре изучения делиберативной демократии в Стэнфорде, руководители которого провели делиберативные форумы среди простых граждан в разных регионах мира. Эти форумы по актуальным политическим вопросам показали одни результаты исследований в разных регионах: умеренное сближение по взглядам, а не разъединение между прежде поляризованными социальными группами, формирование более разумных, продуманных суждений и более рефлексивного общественного мнения после обмена гражданами между собой личными мнениями и аргументами [Fishkin, Luskin 2005].

Таким образом, подтверждаются основные положения Ю. Хабермаса о диалоге в обществе, возможности аргументированного обмена мнениями и сближения после этого чувств и представлений прежде разъединенных людей, когда происходит «вовлечение Другого».

Но, как видно, все эти практические задачи служат осуществлению основополагающей нормативной цели - сохранению не запрограммированной «кон-

1 Примеры таких вопросов: референдумы по Брекситу и по отделению Шотландии, которые затронули взаимно конфликтующие интересы сторон. Более продуманное, вовлекающее все стороны обсуждение, совершающееся по выявленным принципам, может привести к более рациональному, рефлексивному консенсусу, соотносящему интересы всех сторон.

2 Оба типа исследований могут применяться на разных уровнях - самом общем, международном; на мезоуровне - уровне государств; на макроуровне - вопросы, затрагивающие интересы государственных и гражданских институтов, социальных групп; на микроуровне - при личном взаимопонимании между людьми. 
структорами реальности», а подлинной, независимой человеческой личности и раскрытию ее настоящей реальности в собственном жизненном мире.

Затем состоялось обсуждение докладов, посвященных трудам крупного представителя «второй волны» франкфуртской школы социальных исследований ныне здравствующего Юргена Хабермаса.

\section{Список литературы}

Винер Н. 2001. Человеческое использование человеческих существ: кибернетика и общество. - Человек управляющий. СПб: Питер. С. 3-196.

Геллнер Э. 2004. Условия свободы. М.: Изд-во МШПИ. 239 с.

Зиновьев А.О., Чеботарева А.Э. 2013. К оценке французского вклада в «политическую философию науки»: критика Ю. Хабермаса с позиций теории практики. - Мысль: журнал Петербургского философского общества. Т. 15. С. 29-40.

Линде А.Н. 2018. Критический дискурс-анализ и его применение к исследованию обсуждения административных решений в РФ. - Maтериаль VIII Всероссийского конгресса политологов. М.: Аспект Пресс. С. 307-308.

Публичная сфера: теория, методология, кейс стади: коллективная монография. 2013. М.: ООО «Вариант»; ЦСПГИ. 360 с.

Cukier W., Bauer R., Middleton C. 2014. Applying Habermas Validity Claims as a Standard for Critical Discourse Analysis. - Information Systems Research. Relevant Theory and Informed Practice. P. 233-258. IFIPAICT. Vol. 143.

Fishkin J., Luskin. R. 2005. Experimenting with a Democratic Ideal: Deliberative Polling and Public Opinion. - Acta Politica. Vol. 40. P. 284-298.

Müller H. 1995. Spielen hilft nicht immer. Die Grenzen des Rational-ChoiceAnsatzes und der Platz der Theorie kommunikativen Handelns in der Analyse internationaler Beziehungen. - Zeitschrift für internationale Beziehungen. № 2. S. 371-392.

ZINOV'YEV Andrey Olegovich, Cand.Sci. (Pol.Sci.), Associate Professor of the Chair of Theory and Philosophy of Politics, Saint Petersburg State University (7th entr., 1/3 Smolnogo St, St. Petersburg, Russia, 191124; azin73@mail.ru) LINDE Andrey Nikolaevich, Cand.Sci. (Pol.Sci.), Associate Professor of the Chair of Regional Governance and National Policy, Odintsovo Branch of Moscow State Institute of International Relations (University) (4th entr., bld. 4, 9 Ostrovityanova St, Moscow, Russia, 117437; anlinde @ mail.ru)

MIRONOVA Dagmar Vali Gerta, Cand.Sci. (Philos.), Associate Professor of the Chair of History and Theory of Politics, Lomonosov Moscow State University (bld. 4, 27 Lomonosovsky Ave, Moscow, Russia, 119192; dagmar@mail.ru) SYTIN Andrey Georgievich, Cand.Sci. (Philos.), Associate Professor of the Chair of Philosophy of Politics and Law, Lomonosov Moscow State University (bld. 4, 27 Lomonosovsky Ave, Moscow, Russia, 119192; a_sytin@mail.ru)

\section{DIALOGUE AS A PERCEPTION OF THE OTHER IN POLITICS (an analytical review of the reports of the round table,
devoted to the $90^{\text {th }}$ anniversary of J. Habermas)}

Abstract. The scientific reports at the round table presented different aspects of the scientific works of J. Habermas. The contributors analyzed normative themes, such as creative heritage of $\mathrm{J}$. Habermas and the modern political thought, his theory of communicative action and the conception of deliberative democracy, the perception of the state and revolution, the nature of the political and public sphere. The conference proved the applicability of the normative-theoretical conceptions of Habermas in reality: in applied political science and in solving humane social problems in practice.

Keywords: abermas, dialogue, involvement of the Other, application of normative foundations to political science and social reality 